\title{
Riscos e desastres relacionados a eventos extremos (climáticos e meteorológicos) no estado da Paraíba.
}

\author{
Risks and disasters related to extreme events (climatic and meteorological) in the state of \\ Paraíba.
}

\author{
$\operatorname{COSTA}^{1}$, J. N.; SILVA JÚNIOR ${ }^{1}$, J. B.; ARAÚJO² ${ }^{2}$ S. M. S. \\ jnatasnascimento@yahoo.com.br;
}

\begin{abstract}
Resumo
Os desastres caracterizam-se enquanto fenômenos excepcionais ou extremos que afetam diretamente uma dimensão social, econômica, ambiental, políticoinstitucional, etc. Compreendendo a complexidade que envolve os riscos e desastres, o presente estudo, objetivou desenvolver uma analise dos eventos extremos (climáticos-meteorológicos) no estado da Paraíba, relacionando: registros oficiais, tipologias, condicionantes físicos-ambientais, intensidade dos fenômenos, dimensão social impactada, entre outros. Desta forma, constata-se a grande variabilidade tipológica de desastres atuantes no estado, com forte presença de eventos climáticos e meteorológicos. Assim foram identificados os seguintes eventos extremos: Enxurradas, Inundações, Alagamentos, Vendavais, Granizos, Trovoadas, e processos integrados de convecção.
\end{abstract}

Palavras-chave: Riscos; Desastres; Paraíba.

\begin{abstract}
Disasters are characterized as exceptional or extreme phenomena that directly affect a social, economic, environmental, political-institutional dimension, etc. Understanding the complexity that involves risks and disasters, the present study aimed to develop an analysis of extreme events meteorological conditions, intensity of phenomena, social dimension impacted, among others. In this way, we can verify the great typological variability of disasters in the state, with a strong presence of climatic and meteorological events. Thus, the following extreme events were identified: flooding, flooding, flooding, sale, hail, thunderstorms, and integrated convection processes.
\end{abstract}

Keywords: Risk; Disaster; Paraíba.

\section{INTRODUÇÃO}

Os eventos extremos ou intensos são geradores de múltiplos impactos sociais e inclusive, riscos e desastres do tipo hidrológico (inundações, enxurradas e alagamentos), no Brasil somente no ano de 2011 morreram cerca de 890 pessoas por desastres naturais provocados por eventos extremos (BRASIL, 2012), sendo os principais: enxurradas, inundações, vendavais, granizo, alagamentos, tempestades de raios. No estado da Paraíba, no período de 1991 a 2012, foram registrados 2.341 eventos de desastres naturais reconhecidos pelo Sistema Nacional de Proteção e Defesa Civil (SINPDEC), segundo Brasil (2012) a Paraíba no período supracitado, é caracterizada por recorrentes desastres hidrológicos tipo enxurrada, com 215 registros, seguido 136 eventos de inundação, 3 de alagamentos e 1 de vendaval.

Existem várias conceituações e sinônimos para eventos extremos, tempestades convectivas severas e outros termos, nesse trabalho utilizou-se o do viés fenômeno climático e meteorológico desencadeador de riscos e desastres de rápida evolução, definido como: 
[...] Tempestades capazes de gerar fenômenos com significativo impacto social e econômico, e um conceito implícito de que são tempestades com correntes ascendentes e descendentes extremamente intensas e, portanto, capazes de gerar e suportar (em suspensão) granizo gigante, gerar rajadas de vento destrutivas [...] NASCIMENTO (2005, p. 121)

Na região Nordeste e no estado da Paraíba os sistemas padrão para produção de chuvas, são relacionados a uma série de condicionantes do sistema oceano superfície, os mecanismos são: Zona de Convergência Intertropical (ZCIT), Complexos Convectivos de Meso-Escala (CCM), Vórtice Ciclônicos de Ar Superior (VCAN), Sistemas Frontais, Linhas de Instabilidades, Ondas de Leste , Brisas Marítimas e Terrestres, (Molion \& Bernardo, 2000; Nóbrega, 2012).

Em geral, os mecanismos descritos podem gerar eventos extremos, os Complexos Convectivos de Meso-Escala (CCM) são acumulados de nuvens tipo cumulonimbus e cirrus que perfazem círculos observáveis, sua formação é rápida e intensa de 6 a 12 horas, atua nos meses da primavera e de verão (Silva Dias, 1987); Linhas de Instabilidade- distribuídas como bandas de nuvens em forma de linha, com desenvolvimento normalmente ao final da tarde, devido a grande quantidade de radiação acumulada (Molion \& Bernardo, 2000); e outros fenômenos.

Os processos naturais podem servir como ameaça diante cenários ou elementos inseguros, esta ligação faz parte do contexto do risco, segundo Castro (2005) esse elemento de possibilidades distintas, pode desencadear danos resolutos ou não ao homem e aos seus bens, como também, o risco é um efeito da combinação entre casualidade (fenômeno/acidente) e as vulnerabilidades de pessoas ou grupos sociais (MENDONÇA, 2008).

As consequências de uma série de problemas sociais e processos humanos ou naturais pode desencadear um desastre, definido como:

\footnotetext{
Resultado de eventos adversos, naturais ou provocado pelo homem sobre um cenário vulnerável, causando grave perturbação ao funcionamento de uma comunidade ou sociedade envolvendo extensivas perdas e danos humanos, materiais, econômicos ou ambientais, que excede a sua capacidade de lidar com o problema usando meios próprios. (INSTRUÇÃO NORMATIVA, 2012, p.1):
}

Compreendendo a complexidade e as dimensões de impacto dos riscos e desastres, a presente pesquisa objetivou desenvolver uma analise dos eventos extremos (climáticosmeteorológicos) no estado da Paraíba, relacionando: registros oficiais, tipologias, condicionantes físicos-ambientais, intensidade dos fenômenos, dimensão social impactada, entre outros. Ressalta-se que, não entra no escopo deste trabalho, o estudo do fenomeno climatico da estiagem. 


\section{METODOLOGIA}

O trabalho foi iniciado por levantamento bibliográfico em diversas bases literárias e digitais, os dados quantitativos foram extraídos e analisados a partir do Atlas brasileiro de desastres naturais (período de 1991 a 2012/ volume Paraíba), publicado pelo Centro Universitário de Estudos e Pesquisas sobre Desastres (CEPED) da Universidade Federal de Santa Catarina (UFSC), sob coordenação da Secretaria Nacional de Proteção e Defesa Civil (SEDEC). Os dados são baseados em registros do Sistema Integrado de Informações de Desastres (S2ID), plataforma que integra todos os relatórios de desastres reconhecidos no Brasil a partir do ano 1990, foi utilizado também na pesquisa, informações e matérias jornalísticas.

Na elaboração de mapas temáticos foi utilizado a base de dados do Geoportal da Agência Executiva de Gestão das Águas do Estado da Paraíba (AESA) e outros Órgãos como Centro de Previsão de Tempo e Estudos Climáticos. Congregado os dados, foram utilizados os softwares QGis 2.18.3, o programa de computação gráfica CorelDRAW X7®.

\subsection{Caracterização da área de estudo}

A Paraíba é uma das 27 unidades federativas do Brasil, localiza-se na região Nordeste Brasileira (Figura 1), geograficamente disposta entre os paralelos $6^{\circ} 5^{\prime} \mathrm{S}$ a $8^{\circ} \mathrm{S}$ de latitude e os meridianos de $38^{\circ} 5^{\prime} \mathrm{W}$ a $35^{\circ} 00^{\prime} 00^{\prime}$ ' $\mathrm{W}$ de longitude. Possui extensão territorial de $56.468,427 \mathrm{Km}^{2}$ (IBGE, 2017) distribuídos em 223 municípios; com estimativa populacional para o ano de 2016 de 3.999.415 habitantes (IBGE, 2017), uma densidade demográfica de 66,70 (hab./Km²) segundo o Censo 2010 (IBGE, 2017), com população concentrando-se nos principais centros urbanos (João Pessoa, Campina Grande, Santa Rita, Patos e outros).

O Estado da Paraíba é dividido em quatro mesorregiões, que levam em consideração a diversidade de combinação entre os elementos geoambientais (físico-ambientais) da área de estudo: Mata Paraibana, Agreste, Borborema e Sertão.

A Mesorregião da Mata Paraibana possui feições geológicas sedimentares sobre o embasamento cristalino, com aluviões e sedimentos de praia (CPRM, 2002). A Geomorfologia é constituída pelos Tabuleiros costeiros, planícies do tipo fluvial, flúvio-marinha e marinha, com altitudes que variam de 0-500 (AESA, 2010); o clima é do tipo $A s^{\prime}$, tropical chuvoso, com chuvas de outono-inverno, na classificação de Köppen. Possui isoietas (linhas que delimitam áreas que possuem faixas de precipitações ou chuvas), cujas variações estão entre 800 e 1.700 mm/ano. 


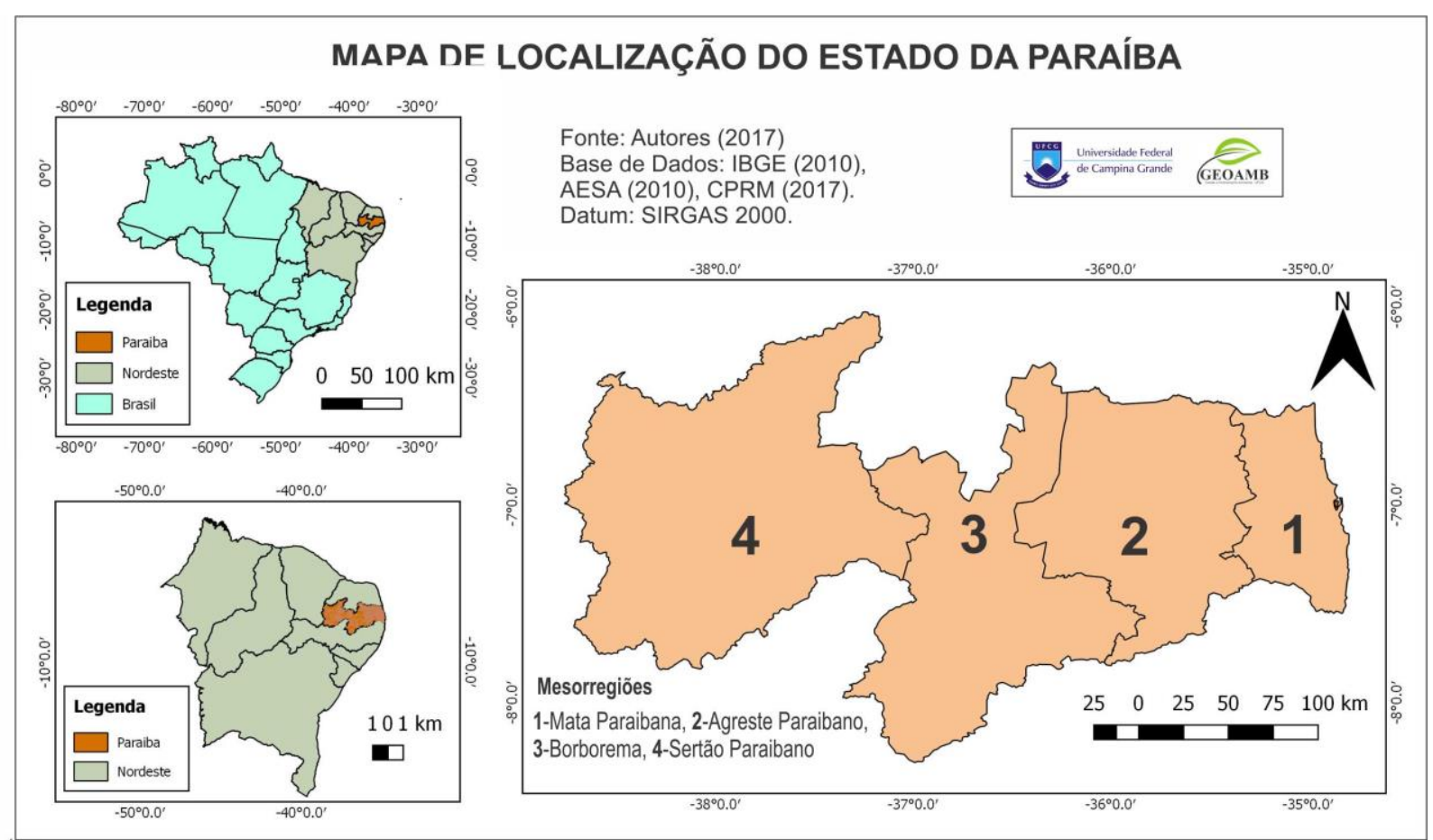

Figura 01 - Mapa de Localização do estado da Paraíba e suas mesorregiões Geográficas. Fonte: Organizado por Jônatas Costa, 2017. Base de dados: IBGE (2010), AESA (2010); CPRM (2017).

Os solos apresentam maior predomínio de Latossolos vermelho-amarelo (distrófico), e menores áreas de Neossolos Flúvicos, Marinhos e Hidromórficos (distróficos), segundo a nova classificação de solos da Empresa Brasileira de Pesquisa Agropecuária. A Hidrografia apresenta padrão dendrítico espaçado, com áreas de foz das bacias hidrográficas dos rios Camaratuba, Mamanguape, Miriri, Gramame, Abiaí e do Paraíba, sendo este último o mais importante do estado (AESA, 2010). A Vegetação é constituída pela Floresta ombrófila densa e aberta, Floresta estacional semi-decidual e decidual, constituindo a Mata Atlântica (RADAMBRASIL, 1987), bastantes degradadas pela agroindústria canavieira e pelo processo de urbanização.

A Mesorregião do Agreste apresenta uma geologia constituída pelo-embasamento da Província Borborema (CPRM, 2002) e sua geomorfologia está representada pela Depressão Sublitorânea, com formas tabulares, e pelo Planalto da Borborema com formas convexas e tabulares (AESA, 2010). As altitudes variam de 300-1000 e o clima é do tipo As', tropical chuvoso com chuvas de outono-inverno, na classificação de Köppen; e com isoietas médias anuais entre 400$1.000 \mathrm{~mm} / \mathrm{ano}$. Os solos presença de Luvissolos crômicos, Planossolos, Vertissolos, Neossolos Litólicos Eutróficos e Neossolos Regolíticos (AESA, 2010). A Hidrografia apresenta padrão dendrítico com direcionamento de fluxos para o leste e sul, tal área compõe as bacias hidrográficas dos rios: Curimataú, Mamanguape, Camaratuba, Jacu, mas, grande área de drenagem do rio 
Paraíba, a vegetação é constituída pela Floresta estacional semidecidual e decidual e de caatinga (AESA, 2010; RADAMBRASIL, 1987).

A Mesorregião da Borborema possui uma Geologia de embasamento da Província Borborema (CPRM, 2002) e a Geomorfologia é composta pelo Planalto da Borborema com formas tabulares e convexas (AESA, 2010), com altitudes que variam de 300-1000 (AESA, 2010). As precipitações variam dos 400 aos 800 mm/ano (AESA, 2010).-Os solos da Borborema são os Neossolos Litólicos Eutróficos, Luvissolos e Vertissolos. A hidrografia apresenta padrão dendrítico com direcionamento de fluxos para o leste e oeste (unicamente a Bacia Piranhas), tal área compõe as bacias hidrográficas dos rios: Piranhas, Jacu, Curimataú, mas, grande área de drenagem do rio Paraíba. Vegetação: Caatinga com variações de Arbustiva a Arbórea e de densidades abertas e fechadas (AESA, 2010, RADAMBRASIL, 1987) (Figura 2).

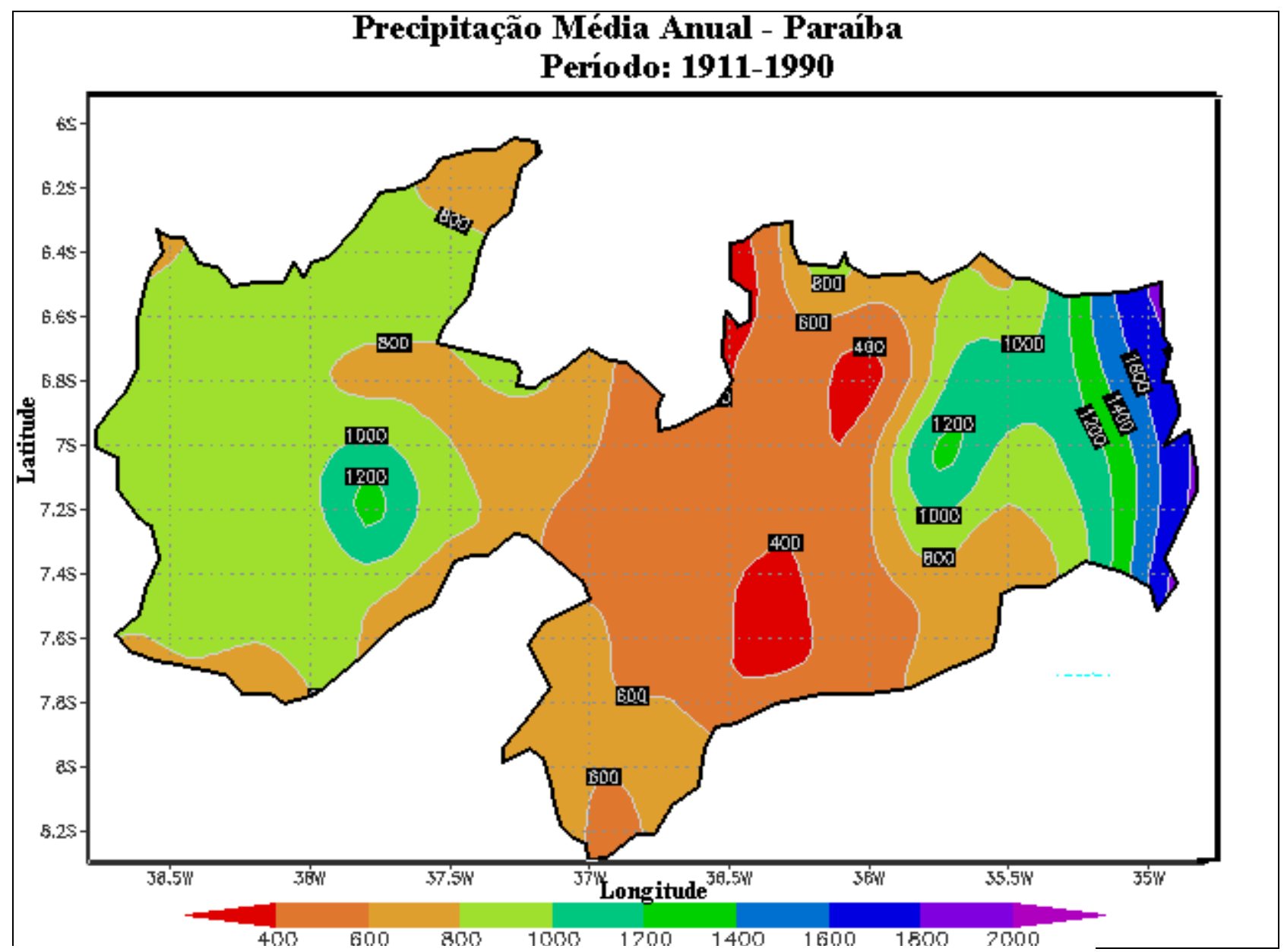

Figura 02- Mapa da distribuição pluviométrica anual do estado da Paraíba (1911-1990). Disponível em: http://www.dca.ufcg.edu.br/clima/mapas/pbanop.gif. Acesso em: 17/11/2017.

A Mesorregião do Sertão apresenta Geologia predominante do embasamento cristalino da Província Borborema, mas com setores a norte e noroeste de sedimentos cretácicos que compõem a Bacia do Rio do Peixe. A Geomorfologia ao norte é formada pela Depressão sertaneja, com formas 
suavemente onduladas e altitudes que variam de 200 a $500 \mathrm{~m}$, e ao centro-sul é formada pelo Planalto sertanejo com formas aguçadas e erosivas com altitudes que vão de 500 a $1200 \mathrm{~m}$. O clima é do tipo $A w$, tropical chuvoso com pluviometria que varia dos 500-1100 mm/ano (CPRM, 2002; AESA, 2010). Os solos mostram um predomínio dos Neossolos Litólicos Eutróficos, Luvissolos crômicos, Vertissolos, Cambissolos e diversas áreas de afloramentos rochosos que caracterizam alinhamentos serranos. A hidrografia apresenta padrão dendrítico denso, a maior ramificação de drenagem do estado com direcionamento de fluxos para o oeste e norte, tal área compõe a bacia hidrográfica do rio Piranhas. A vegetação é de caatinga variando de arbórea a arbustiva, com densidades abertas e fechadas apresentando relevante degradação pelo antropismo. (RADAMBRASIL, 1987; AESA, 2010).

\section{RESULTADOS E DISCUSSÃO}

Os desastres naturais na Paraíba sob registro no S2ID no período de 1991-2012, tratados nesse trabalho, são analisados a partir de processos extremos, uma analise interessada nas intensas ou elevadas quantidades de chuvas e as suas respectivas distribuições espaciais homogêneas, como também, a visão meteorológica voltada ao estudo das variáveis atmosféricas e seus fenômenos dinâmicos e locais, a partir dos elementos temperatura, chuva, vento, umidade e outros (CPTEC; 2017),

Portanto, o Clima e o Tempo, podem ser promotores de vários tipos de eventos extremos, na qual nesse trabalho, serão analisados os principais recorrentes na Paraíba, elencados em: I) riscos e desastres hidrológicos (inundação, enxurradas e alagamentos), II) vendaval, III) granizo e trovoadas, e IV) fenômenos integrados e em diferentes escalas.

\subsection{Riscos e desastres hidrológicos}

Segundo a Codificação Brasileira de Desastres (COBRADE) e alguns autores os desastres hidrológicos são divididos em: Inundações ou Inundações graduais- caracterizados pela elevação anormal do curso de água para áreas que normalmente não se encontram submersas, essa ascensão hidrológica decorre gradualmente, ocasionado geralmente por chuvas prolongadas em áreas geralmente de planícies (BRASIL 2011; GOERL \& KOBIYAMA, 2005); Enxurradas ou Inundações bruscas- caracterizadas pela rápida e volumosa quantidade de água escoada de forma concentrada em pequenas bacias hidrográficas ou em áreas de altas declividades, provocados por chuvas intensas e concentradas, apresenta significante poder destrutivo pela rápida evolução, encontrando normalmente comunidades ribeirinhas despreparadas (BRASIL 2011; GOERL; 
KOBIYAMA, 2005); Alagamentos - é a exceção da capacidade regular dos sistemas de drenagem no meio urbano, gerando acumulação momentânea de água pontualmente ou em áreas maiores, em decorrência de precipitações intensas (BRASIL 2011; SANTOS, 2012).

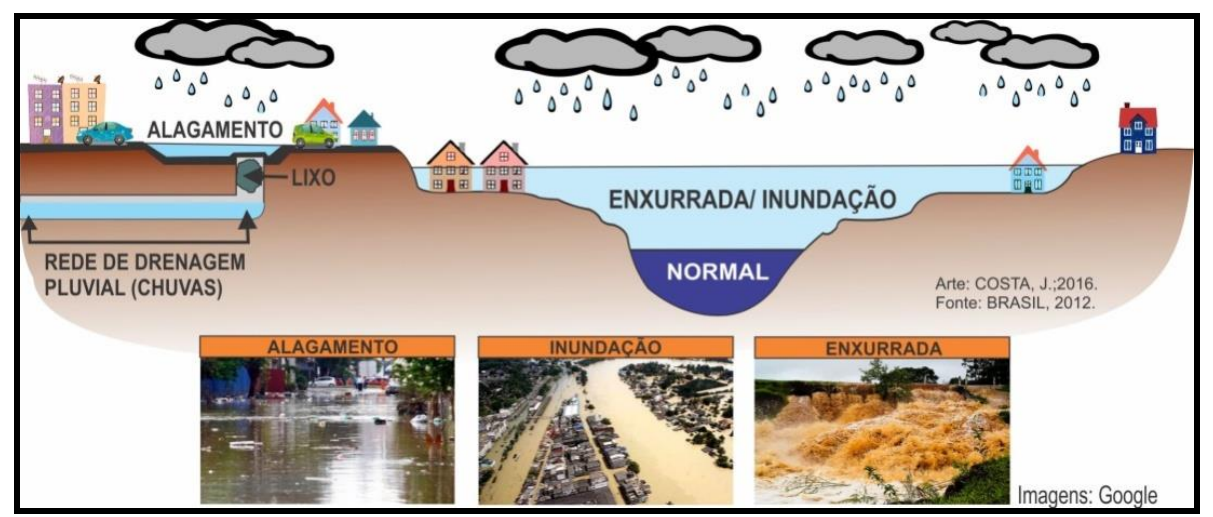

Figura 03 - Desastres hidrológicos. Arte: Jonatas Costa, 2016.

A distribuição e ocorrência dos desastres hidrológicos estão associadas aos processos climatológicos e meteorológicos de cada área geográfica; para tanto, discorre-se a seguir cada tipologia hidrológica, registros e os condicionantes físico-ambientais, relacionáveis a estes processos de riscos naturais.

\section{1 - Enxurradas}

Na Paraíba foram 215 ocorrências de enxurradas, ocupando assim o fenômeno hidrológico mais recorrente no estado, figura $4 \mathrm{~B}$.

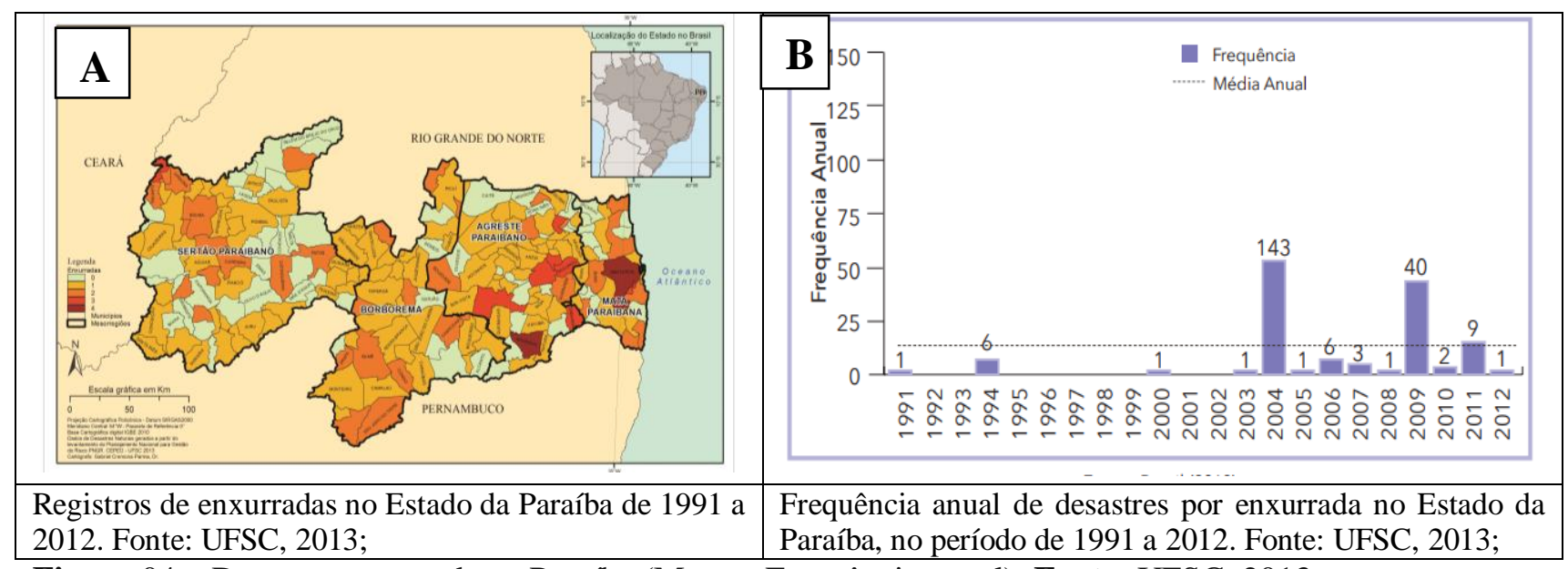

Figura 04 - Desastre enxurrada na Paraíba (Mapa e Frequência anual). Fonte: UFSC, 2013.

Esses são proporcionados muita das vezes, por outro fenômeno, de ordem meteorológica, denominado aguaceiro, uma variação das tempestades tropicais, os aguaceiros tem curta duração, 
muito intenso, e atrelado a ventos fortes, raios e trovoadas, e podendo ter cristais de gelo (granizo), e sua duração é de 1 a 2 horas (AYOADE, 2012).

Também, deve-se considerar que podem existir outros processos meteorológicos que provocam as enxurradas; Entretanto, destaca-se que os significantes volumes precipitados de forma intensa, normalmente geram enxurradas em áreas com as seguintes características: a) Áreas de relevo com altas declividades aumentam a velocidade dos fluxos para áreas planas; b) tipos de precipitação, como orográficas e convectivas proporcionam maior ocorrência de enxurradas e como volume maior em curto espaço temporal, ambas comuns na área pesquisada; c) cobertura vegetal espaçada e rarefeita, que reduzem o impacto/velocidade das precipitações e a sua ausência é um agravante no cenário vulnerável; d) capacidade de drenagem com bacias de pequeno porte $(<500$ $\mathrm{Km}^{2}$ ). (TUCCI, 2007; UFSC, 2013).

Estes fatores, citados acima, aliados às interferências humanas, como exemplo a impermeabilização do solo, são os principais potencializadores para desastres hidrológicos, principalmente os de enxurradas. Outra característica ambiental na área estudada, que cabe ressaltar para a análise da dinâmica natural, são as áreas com relevos de declividades superiores a $45 \%$ e podendo apresentar solos pedregosos e afloramentos rochosos, o que segundo Tricart (1977) considera como setores para enxurradas e escoamento superficial concentrado, estes tipos de meios são peculiares nas áreas do Agreste, Borborema e Sertão, reforçando assim os registros. Uma excepcionalidade das ocorrências de enxurradas foram os rompimentos de barragens na Paraíba, geralmente de pequeno porte, mas, a de grande monta gerando danos/prejuízos foi a da barragem de Camará (Alagoa Nova-PB, Agreste), no ano de 2004, impactando diretamente mais quatro (4) municípios, todavia, as precipitações intensas e a alta declividade da região colaboraram para maiores impactos.

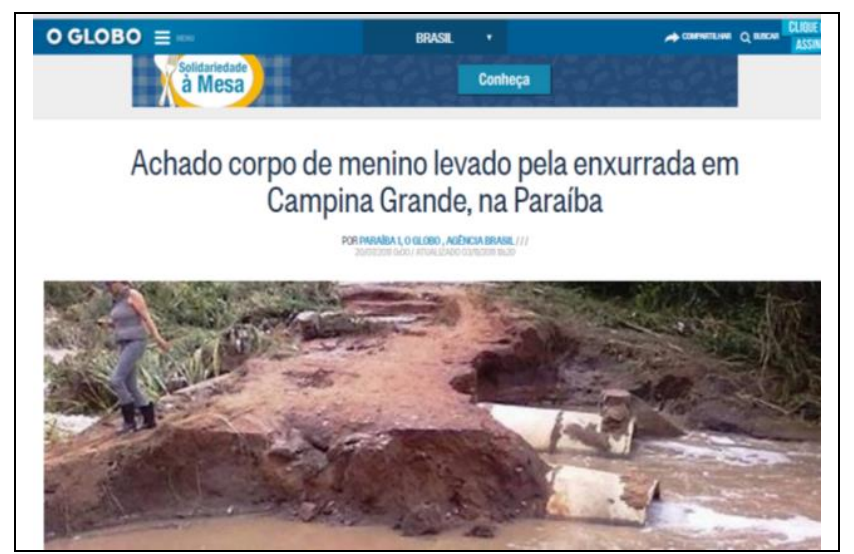

Figura 05 - Matéria da morte de criança causada por enxurrada em Campina Grande-PB. Fonte: Disponível em: https://oglobo.globo.com/brasil/achado-corpo-de-menino-levado-pela-enxurrada-em-campina-grandena-paraiba-2713273. Acesso em: 17/11/2017. 
O fenômeno de enxurrada na Paraíba, assim como outros riscos e acidentes, por vezes, não chega ser considerado como desastre, estabelecido por critérios técnicos e de reconhecimento por parte do SINPDEC, como o caso da morte do menino de 10 anos morador do bairro Mutirão (Campina Grande-PB) no ano de 2011, onde o mesmo, residia nas margens de um curso d'água e após chuvas fortes e o rompimento de barragens á montante, provocou a enxurrada, o fato promoveu comoção no município e veiculação na mídia nacional (Figura 5).

\subsection{Inundações}

Na Paraíba, totalizaram 136 ocorrências reconhecidas como desastre. As áreas mais recorrentes são, naturalmente, as planícies próximas a riachos e rios, chamadas de bacias ou planícies de inundação (IBGE, 2009), que a partir de fenômenos meteorológicos, há um aumento gradual do nível fluvial extravasando progressivamente para suas margens, realizando uma avaliação macro-escalar. As duas mesorregiões de maior vulnerabilidade às inundações, são a Mata e o Sertão, por deterem relevos aplainados, proporcionando, assim, maior tempo de acúmulo em áreas marginais aos rios e córregos, caso mostrado na figura 7A. Outra informação é que o desastre de inundação na Paraíba, durante os anos publicados (1991-2012), está associado, normalmente, aos períodos de chuvas acima das médias históricas, nos casos de 2008 a 2011, figura 6B.

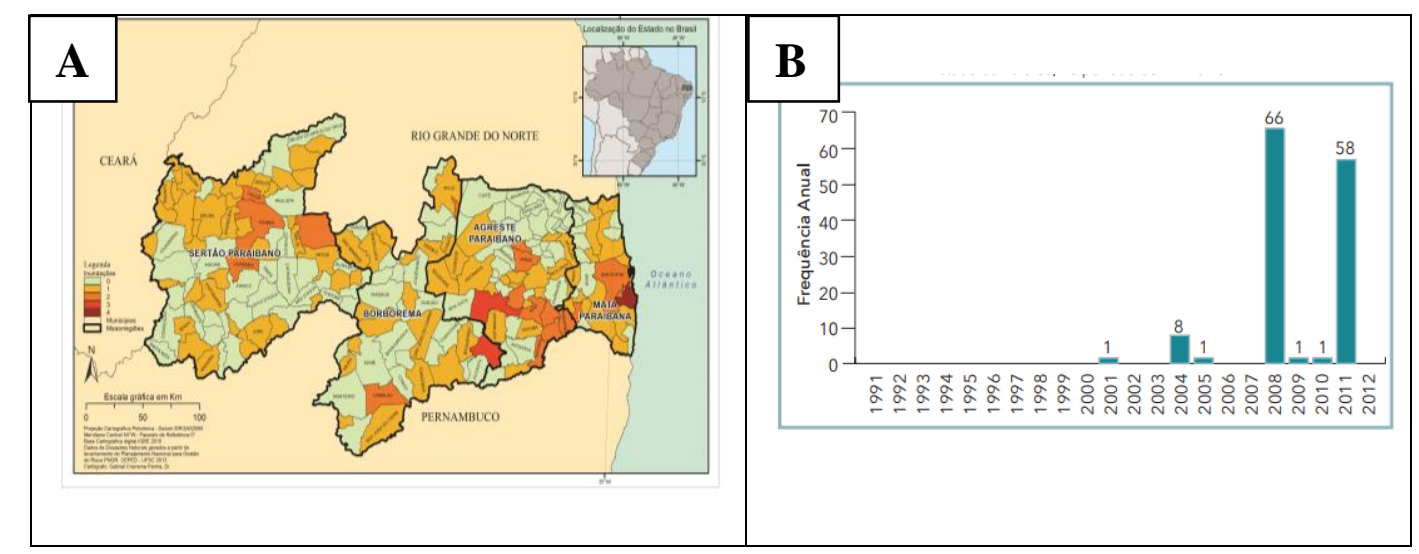

Figura 06 - Desastre inundação na Paraíba (Mapa e Frequência anual). Fonte: UFSC, 2013.

\subsection{Alagamentos}

Desastre hidrológico associado á eventos extremos de menor quantificação no estado, são os, com somente três (3) registros oficiais (UFSC, 2013), localizados na zona da Mata paraibana (municípios de Cabedelo e Lucena). Estes associados a problemas de mau dimensionamento de rede de drenagem pluvial, obstrução por sólidos, ou até mesmo inexistência de drenagem pluvial em áreas urbanizadas. Os alagamentos comumente têm origem a partir dos mesmos processos 
meteorológicos citados, mas que, nos grandes centros urbanos do estado, chuvas de pequena intensidade podem ser motivadoras de alagamentos (Figura 5), demonstrando, assim, uma problemática no campo da engenharia civil e urbanização. Destaca-se que, apesar do evento alagamento ser comum nos centros urbanos ou não, este só chegou a ser quantificado e reconhecido como desastre em 3 eventos no período analisado (1991-2012).

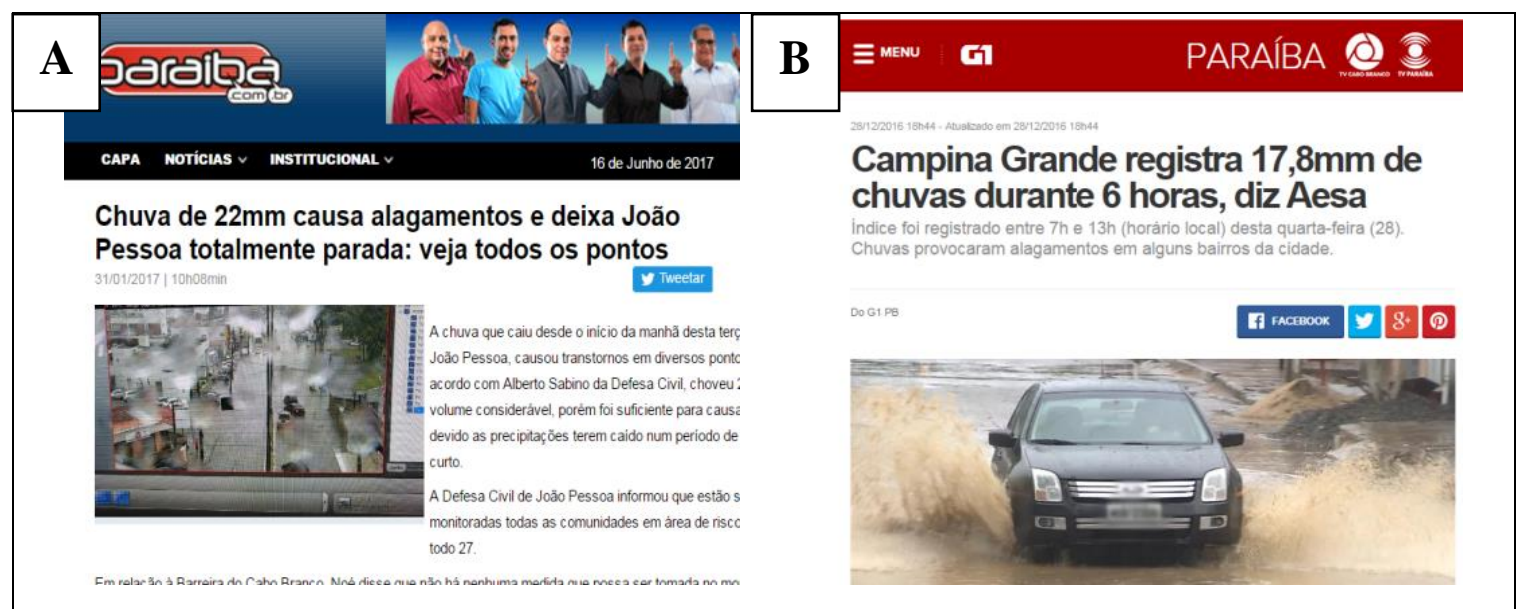

Figura 07 - Alagamentos em grandes centros urbanos da Paraíba, associados a pequenas quantidades de chuvas. Fonte: Paraíba.com.tv, janeiro/2017; G1- Paraíba, dezembro/2016.

\subsection{Vendaval}

Os Vendavais são fenômenos meteorológicos, no o qual está ligado às tempestades e convecções locais segundo COBRADE, que conceitua o mesmo, como um fenômeno de intenso deslocamento da massa de ar interagindo com a superfície de uma área, os vendavais são fortes rajadas de ventos, ultrapassando $65 \mathrm{Km} / \mathrm{h}$ segundo a Escala de Beaufort, que classifica as velocidades dos ventos e seus efeitos em elementos sociais, agindo normalmente de forma pontual, como nos casos da figura 8, a figura 8A mostra um caso recente na qual os danos foram relevantes e o fato foi tão pontual, que segundo a AESA não foi registrado nenhum indicio de rajadas de ventos nos equipamentos do sertão, da mesma forma do caso da figura $8 \mathrm{~B}$, o deslocamento e lançamento de telhas de prédios do conjunto Major Veneziano em Campina Grande-PB.

Os condicionantes físico-ambientais para vendavais estão associados a princípios atmosféricos e suas dinâmicas, mas os impactos de vendavais, principalmente nas áreas urbanas, estão correlacionados a duas condições artificiais gerados pela ação humana. A primeira se dá pela retirada de vegetação que funciona como redutor (atrito) para o deslocamento de ar; segundo, a ocupação de áreas de relevo mais altos que recebem regularmente maior ventilação, e estas edificações não levam em consideração aspectos técnicos construtivos e informações meteorológicas da área, como cartas de direção e velocidade dos ventos (STIPP, 1997). No estado 
foi registrado e reconhecido como desastre, um (1) episódio de vendaval no período publicado (1991-2009), situação adversa registrada na cidade de Conceição (Sertão Paraibano), com ventos variando até $100 \mathrm{~km} / \mathrm{h}$ e chuvas intensas em curto intervalo de tempo, impactando 17.931 pessoas e 50 desalojadas (UFSC, 2013).

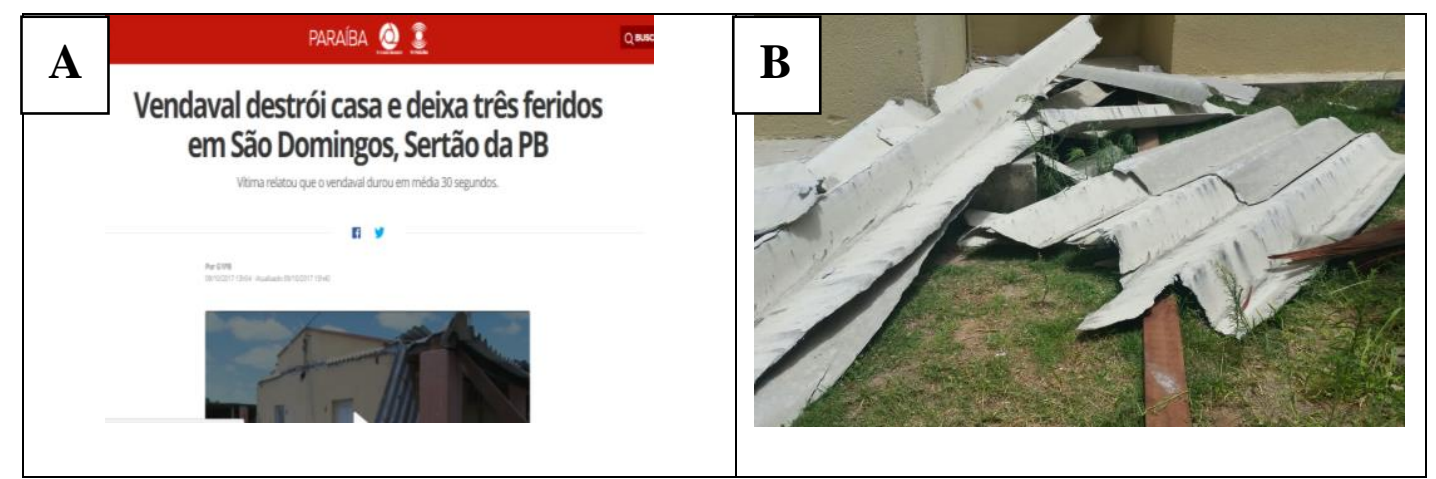

Figura 08 - Casos de ventania em setores pontuais espacialmente. Fonte: G1 PB, outubro/2017; Foto: autor/2016.

\subsection{Granizo e trovoadas}

O Granizo, consiste em um fenômeno meteorológico extremo é originado na nuvem cumulonimbo, sendo um tipo de precipitação, onde variados grânulos de gelo caem em formatos múltiplos, normalmente de bolas ou pedaços irregulares (CPTEC, 2017).

As Trovoadas são eventos extremos que é provocado por trovão (violento e forte som emitido pela pressão atmosférica) combinado com relâmpago (processo luminoso gerado com descargas elétricas entre as nuvens e nuvens e solo), o evento das trovoadas pode ser associados com ou sem chuva, (CPTEC, 2017).

Não existe no período analisado registro de desastres causados por granizo e por trovoadas, o que existe são registros informais dos dois fenômenos relacionados a processos convectivos extremos, que serão abordados mais a diante.

\subsection{Fenômenos integrados e em diferentes escalas}

Os eventos extremos na Paraíba, assim como todo o semiárido nordestino (ARAUJO, 2006), agem frequentemente de gênese integrada, por processos de meso-escala ou de micro-escala. Os principais aguaceiros provocam raios, trovões, granizo e vendaval. Estes são fenômenos cada vez mais recorrentes, devido aos principais sistemas climáticos que atuam nas áreas citadas, a ZCIT (Zona de Convergência Intertropical), seguida pelos Complexos Convectivos de Mesoescala (CCMs) e, em menor escala, a célula convectiva individual cúmulos nimbus (AYOADE, 2012), ambas de rápida formação, propiciadas amplamente, pelas diferenças termodinâmicas entre a superfície (quente) e atmosfera (úmida) intensificando as trocas de ar ascendente e descendente, sob condições de perturbações atmosféricas (AYOADE, 2012), o processo de forma geral é processado 
na figura 9A, e na figura 9B um caso de formação de célula convectiva no município de Campina Grande, demonstrando rápida formação (aprox.45min) gerando grandes transtornos sociais, acompanhados de chuva, ventania, trovões e raios num curto espaço de tempo;

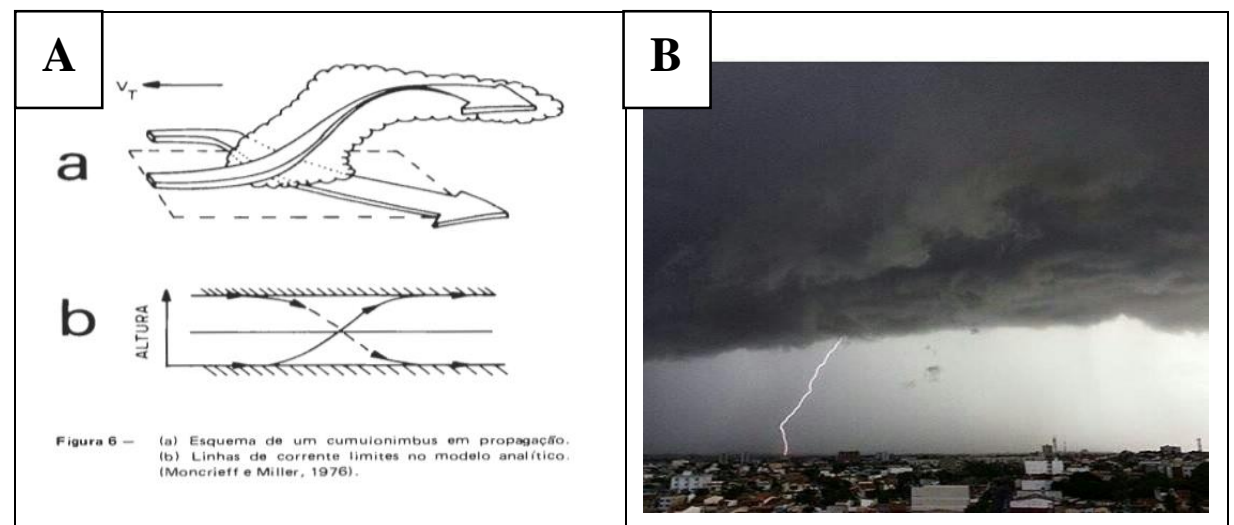

Figura 09 - Formação de células convectivas. Fonte: Nascimento (2005). Foto: Arquivo pessoal, 22/03/2017.

As características acima mencionadas são comuns em todas as mesorregiões da Paraíba, preferencialmente no inicio de cada um de seus períodos chuvosos; exemplo desta razão física são os repetidos eventos extremos em Campina Grande - PB (Agreste) no mês de março, como mostra na figura 10. Cabe ressaltar que estes fenômenos reincidentes no tempo e no espaço não chegaram a ser considerados desastres por não atenderem critérios técnicos do Sistema de Proteção e Defesa Civil do Brasil.

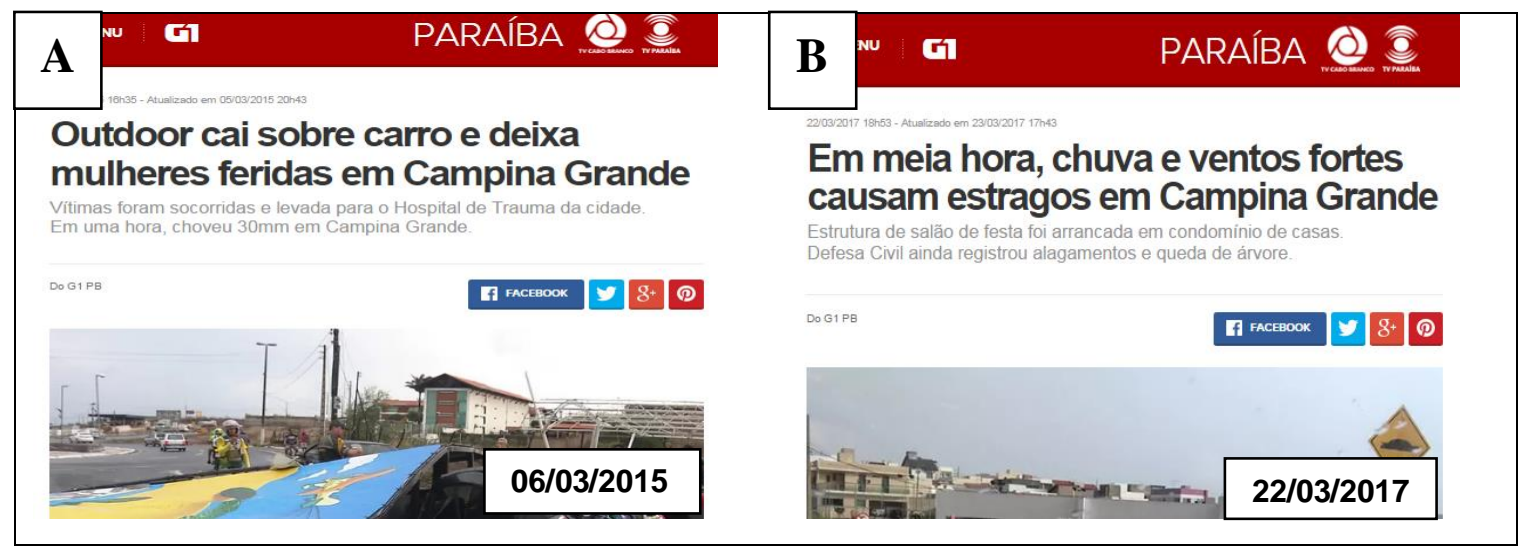

Figura 10 - Eventos extremos no município de C. Grande em anos diferentes com reincidência de fenômenos no mesmo mês. Fonte: G1 Paraíba. Junho/ 2017.

Por fim, com relação a previsibilidade dos eventos extremos, cabe a integração técnica e cientifica para formulação de planejamentos, estratégias e monitoramento climatico e meteorologico, como o sistemas do CPTEC de monitoramento para formação de sistemas convectivos e prevenção de tempestades (Figura 11A), o monitoramento de ameaças naturais dos 
municipios brasileiros por parte do Centro Nacional de Monitoramento e Alertas de Desastres Naturais (CEMADEN), que a partir de modelos, radares, e métodos, enviam-se alertas de riscos e desastres como o caso do dia 06 de março de 2015 para o município de Campina Grande (Figura 11B); e propõe o fortalecimento e disseminação para uso da plataforma Alert-AS do Instituto Nacional de Meteorologia (INMET), cujo projeto é conveniado pela Organização das Nações Unidas (ONU) e países para prevenção e previsão de desastres naturais na América do Sul, figura $11 \mathrm{C}$.

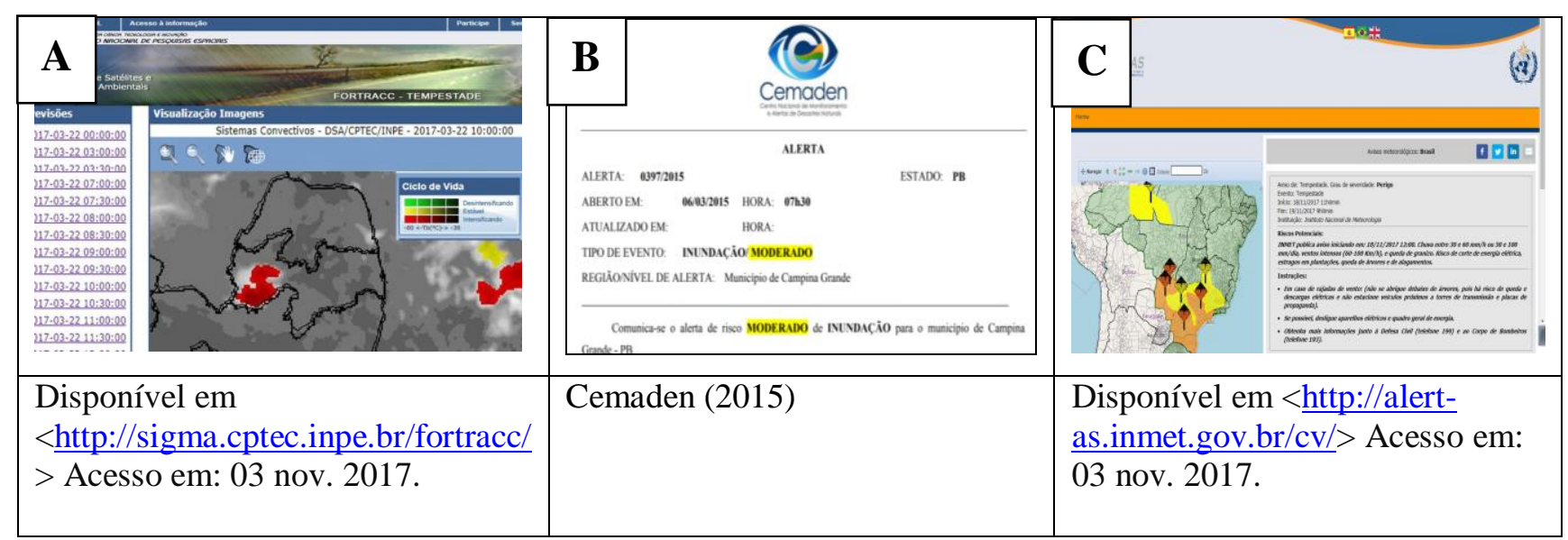

Figura 11 - Instrumentos técnicos-cientiificos que auxiliam o gerenciamento dos riscos e desastres. Organizado por COSTA, 2017.

\section{CONSIDERAÇÕES FINAIS}

Compreendendo a diversidade físico-ambiental do território do estado da Paraíba, os principais eventos climáticos atuantes e a ampla disparidade socioeconômica e tecnológica, tem-se registrado uma amplitude de eventos extremos e gerando danos das mais variadas magnitudes sociais, econômicas, humanas, ambientais. Nesta perspectiva possibilitou-se no referido estudo mediante o levantamento de dados a abrangência espacial de cada uma das tipologias de desastres registradas no período analisado.

Nesta lógica, enfatiza-se que o referido estudo, mediante o diagnóstico desenvolvido favorece preliminarmente o desenvolvimento de ações que minimize os efeitos destes eventos, fortalecendo assim a resiliência das comunidades afetas, que geralmente dispõe de baixo desenvolvimento tecnológico para superar os danos desencadeados durante os desastres. Assim detectou-se que os desastres, podem operar tanto de forma escalar isolada (microescala) ou de forma integrada quando este pode afetar também em mesoescala. 


\section{REFERÊNCIAS}

Novo GEOSGB CPRM. 2017. Disponível em: http://geosgb.cprm.gov.br/. Acesso em: 01. dez. 2017. - Manual técnico de geomorfologia. IBGE, Coordenação de Recursos Naturais e Estudos Ambientais. - 2. ed. - Rio de Janeiro : IBGE, 2009. 175p

AGENCIA EXECUTIVA DE GESTÃO DAS ÁGUAS DO ESTADO DA PARAÍBA - AESA. Geoportal AESA. 2010. Disponível em: http://geo.aesa.pb.gov.br/ Acesso em: 03 nov. 2017.

ARAÚJO, L. E. Análise estatística de chuvas intensas na bacia hidrográfica do rio Paraíba. Dissertação (Mestrado em Meteorologia) - Universidade Federal de Campina Grande, Campina Grande, 2006. 94f.

ARAÚJO, P.H.C. Eventos climáticos extremos: os efeitos dos fenômenos El Niño e La Niña sobre a produtividade agrícola nas regiões Nordeste e Sul do Brasil. Dissertação (Mestrado em Economia Aplicada) - Universidade Federal de Viçosa, Viçosa. 2012. 55f.

AYOADE, J. O. Introdução à climatologia para os trópicos. Editora Bertrand Brasil, Rio de Janeiro, 320 p. 2012.

BARRETO, Raquel. Identificação de áreas susceptíveis a eventos extremos de chuva no Distrito Federal. Brasília, 2008. Dissertação (Mestrado em Geografia), Instituto de Ciências Humanas, Departamento de Geografia, Universidade de Brasília. 162p.

BECKER, C. T.; MELO, M. M. M. S.; COSTA, M. M. N.; RIBEIRO, R. E. P. Caracterização Climática das Regiões Pluviometricamente Homogêneas do Estado da Paraíba. Revista Brasileira de Geografia Física, Ano 02, vol. 04. Recife. 2011, p. 286-299.

BRASIL. Ministério da Integração Nacional. Secretaria Nacional de Defesa Civil. Anuário brasileiro de desastres naturais: 2011 - Centro Nacional de Gerenciamento de Riscos e Desastres.

- Brasília: CENAD, 2012. 82p.

CASTRO, C.M. ,PEIXOTO, M.N.O., RIO, G.A.P. Riscos ambientais e Geografia: Conceituações, abordagens e escalas. Anuário do Instituto de Geociências - UFRJ (Rio de Janeiro: UFRJ), v.282, p. 11-30, 2005.

CPRM - Serviço Geológico do Brasil. Geologia e Recursos Minerais do Estado da Paraíba. 2002. Organizado por Edilton José, Cícero Alves, José Maria Ferreira. Recife: CPRM, 2002. 234f.

CPTEC - Centro de Previsão de Tempo e Estudos Climáticos. Glossário Técnico CPTEC. 2017. Disponível em : http://www.cptec.inpe.br/glossario.shtml. Acesso em: 04 jun. 2017.

FERREIRA, A. G.; MELLO, N. G. S. Principais Sistemas Atmosféricos Atuantes sobre a Região Nordeste do Brasil e a Influência dos Oceanos Pacífico e Atlântico no Clima da Região. Revista Brasileira de Climatologia, v. 1, p. 15-26, 2005.

GOERL, R.F.; KOBIYAMA, M. Considerações sobre as Inundações no Brasil. XVI SIMPÓSIO BRASILEIRO DE RECURSOS HÍDRICOS, 2005, João Pessoa. Anais. Porto Alegre, ABRH, 2005. 
IBGE. INSTITUTO BRASILEIRO DE GEOGRAFIA E ESTATISTICA. 2016. Disponível em: <http://www.ibge.gov.br/estadosat/perfil.php?sigla=pb> Acesso em: 30 mai 2017.

INSTRUÇÃO NORMATIVA n. 1, de 24 de agosto de 2012. Diário Oficial da União. Seção 1, n. 169, quinta-feira, 30 de agosto de 2012. Disponível em: http://bibspi.planejamento.gov.br/bitstream/handle/iditem/208/Instru\%C3\%A7\%C3\%A3o\%20Nor mativa $\% 20$ n1\%2c\%20de $\% 2024 \% 20$ agosto $\% 20 \mathrm{de} \% 202012$.pdf?sequence=1 . Acesso em: 09 nov. 2017.

MENDONÇA, F.; LEITÃO, S. A. M. Riscos e vulnerabilidade socioambiental urbana: uma perspectiva a partir dos recursos hídricos. GeoTextos, 2008. Salvador, v. 4, n. 1-2, p. 145-163.

MOLION, L. C. B.; BERNARDO, S.O. Dinâmica das chuvas sobre o Nordeste brasileiro, In: XI CONGRESSO BRASILEIRO DE METEOROLOGIA. Anais Sociedade Brasileira de Meteorologia - SBMET CL00132, Rio de Janeiro, RJ, 2000.

NASCIMENTO, Ernani de Lima. Previsão de tempestades severas Utilizando-se parâmetros convectivos e modelos de mesoescala: Uma estratégia operacional adotável no Brasil? Revista Brasileira de Meteorologia, v. 60, n. 1, p. 121-140, 2005.

NÓBREGA, José Nildo. Eventos extremos de precipitação nas Mesorregiçoes do estado da Paraíba e suas relações com a TSM dos oceanos Atlântico e Pacifico. Dissertação (Mestrado em Meteorologia), Centro de Tecnologia e Recursos Naturais (Unidade Academica de Ciencias Atmósfericas - UACA), Universidade Federal de Campina Grande, Campina Grande-PB, 2012. 96 f.

RADAMBRASIL, BRASIL. Ministério das Minas e Energia, Secretaria Geral. Projeto RADAMBRASIL. Folhas. 24/25. Jaguaribe/Natal; geologia, geomorfologia, pedologia, vegetação e uso potencial da terra. Rio de Janeiro, 744 p. 7 mapas. 1987.

SANTOS, A. Riscos geomorfológicos e hidrológicos em Aracajú. Alizete dos Santos. Dissertação de Mestrado - Universidade Federal de Sergipe, p. 117. 2012.

SANTOS, C. A. C; BRITO, J. I. B. Análise dos índices de extremos para o semi-árido do Brasil e suas relações com TSM e IVDN. Revista Brasileira de Meteorologia, v. 22, p. 303-312, 2007.

SANTOS, N. A. ; SIQUEIRA, A. H. B. ; BEZERRA, K. L. T. ; CASTRO, C P Q ; MELO, M. L. D. . Eventos extremos: analise do evento ocorrido em junho de 2010 na costa leste do Nordeste Brasileiro. In:. Anais do VI Semana de Meteorologia: Seminário 'atmosfera e os impactos socioeconômicos', 2011.

SILVA DIAS, M. A. F.;: Sistemas de Mesoescala e Previsão de Tempo a Curto Prazo. Revista Brasileira de Meteorologia. 1987, 2, 133-150.

SILVA, D. F.; GALVÍnCIO, J. D. Estudo da Influência da Oscilação Decadal do Pacífico no Nordeste do Brasil. Revista Brasileira de Geografia Física. v. 04, p. 665 - 676, 2011.

STIPP, M. E. F. Impactos Ambientais provocados por vendavais em áreas urbanas. In: VI Encontro de Geógrafos da América Latina - Territórios em Redefinicion - Lugar y Mundo en América Latina, Buenos Aires. Territorios en Redefinición Lugar y Mundo en América Latina Resúmenes Sesiones de Temas Libres, 1997.

TRICART, J. Ecodinâmica. Rio de Janeiro, FIBGE/SUPREN. 1977. 91p. 
TUCCI, C.E.M.; SILVEIRA, A.L.L. Hidrologia: ciência e aplicação. $4^{\mathrm{a}}$ ed. Porto Alegre: UFRGS/ABRH. 2007. 943p.

Universidade Federal de Santa Catarina. Atlas brasileiro de desastres naturais: 1991 a 2012.Centro Universitário de Estudos e Pesquisas sobre Desastres.; Vol. Paraíba / Centro Universitário de Estudos e Pesquisas sobre Desastres. 2 ed. rev. ampl. - Florianópolis: CEPED UFSC, 2013. 105 p. :il. color.; 22 cm. Volume Paraíba.

Universidade Federal de Santa Catarina. Relatório de danos materiais e prejuízos decorrentes de desastres naturais no Brasil: 1995 - 2014.Centro Universitário de Estudos e Pesquisas sobre Desastres. Centro Universitário de Estudos e Pesquisas sobre Desastres; Banco Mundial [Organização Rafael Schadeck] - Florianópolis: CEPED UFSC, 2016. 230 p.: il. color.; 20,5 cm.

VAREJÃO-SILVA, M. A. Meteorologia e Climatologia. PAX Gráfica e Editora Ltda, 2a Edição, 532 p., 2001

\section{AGRADECIMENTOS}

À Defesa Civil de Campina Grande, GEOAMB - Grupo de Pesquisa em Gestão e Ordenamento Ambiental da UFCG e ao GENAT - Grupo de Pesquisa em Gerenciamento dos Riscos e Desastres Naturais da UFRN.

Recebido em: 05/04/2018

Aceito para publicação em: 09/05/2018 